\title{
A Systems Approach Framework for the Transition to Sustainable Development: Potential Value Based on Coastal Experiments
}

\author{
$\underline{\text { Tom S. Hopkins }}^{1,2}{ }^{\text {Denis Bailly }}{ }^{3}, \underline{\text { Ragnar Elmgren }}^{4}$, Gillian Glegg ${ }^{5}, \underline{\text { Audun Sandberg, and Josianne G. Støttrup }}^{6}$
}

\begin{abstract}
This article explores the value of the Systems Approach Framework (SAF) as a tool for the transition to sustainable development in coastal zone systems, based on 18 study sites in Europe, where the SAF was developed and tested. The knowledge gained from these experiments concerns the practical aspects of (a) governance in terms of policy effectiveness, (b) sustainability science in terms of applying transdisciplinary science to social-ecological problems, and (c) simulation analysis in terms of quantifying dysfunctions in complex systems. This new knowledge can help broaden our perspectives on how research can be changed to better serve society. The infusion of systems thinking into research and policy making leads to a preference for multiissue instead of single-issue studies, an expansion from static to dynamic indicators, an understanding of the boundaries between system-dependent and system-independent problems, and the inclusion of non-market evaluations. It also develops a real partnership among research, management, and stakeholders to establish a quantitative basis for collaborative decision making. Furthermore, the article argues that the transition to sustainable development for coastal systems requires consideration of the scale interdependency from individual to global and recognition of the probable global reorganizational emergence of scalefree networks that could cooperate to maximize the integrated sustainability among them.
\end{abstract}

Key Words: coastal zones; integrated coastal zone management; non-market valuation; scale-free networks; simulation analysis; sustainability science; sustainable development; systems approach; transdisciplinary assessments

\section{INTRODUCTION}

This article provides a synthesis of the sequence of articles in this special issue on the value of the Systems Approach Framework (SAF) as an open methodology for evaluating sustainable development and as a specific tool for Integrated Coastal Zone Management (ICZM). Hopkins et al. (2011) explain how the SAF was developed and tested via its application at 18 coastal study sites in the European region (Fig. 1), as part of the European Union (EU) FP6-funded project "Science and Policy Integration for Coastal Systems Assessments" (SPICOSA; http://www.spicosa.eu/). Our synthesis focuses on the SAF value in terms of the knowledge gained from these experiments and how this knowledge relates to broader issues. We further provide perspectives on how the SAF enriches our perceptions concerning sustainable development of other systems and at multiple scales.

The study-site results provide practical examples of how a transition to sustainable development can be addressed in a systematic way, regardless of temporal or geographic conditions. This is relevant to the EU emphasis on sustainable development, backed by a strong research history (e.g., European Land-Ocean Interactions Studies). The choice is aided by the extensive non-statutory structure of ICZM and represents a moderate scale in terms of social-ecological complexity. The purpose of engaging a large number of study sites in the experiment was to better evaluate the effectiveness of the SAF application to a diverse range of coastal zones and to determine whether this diversity generated differences in policy effectiveness (Ostrom et al. 2007).

The SAF experiment tested whether the systems approach could be of value in assisting the transition to sustainable development in coastal zone systems. The need to develop a practical framework follows from the perceived lack of assessment methodologies suitable for addressing the management issues observed in complex coastal systems (cf. Gallopin 2003, Fiksel 2006). The SAF builds on the concepts of the system approach, and on the emerging principles dealing with complex systems, with the aim of providing an open methodology that can self-evolve.

The systems approach is a strategy for improving our understanding of how complex systems function. It allows us to investigate responses of complex systems in situ instead of analyzing them part by part, which has characterized the historical approach. This reflects the systems theory caveat that understanding the structure (composition) does not necessarily permit an understanding of the function (dynamic purpose). Consequently, investigating a system's interactions can increase our understanding of its function beyond that gained by information only on the status of its components. Treating coastal zones as complex systems necessitates the inclusion of the ecological, social, and economic dimensions. We consider the SAF to be a start-up methodology that addresses the "how to" gap between sustainable management

\footnotetext{
${ }^{1}$ North Carolina State University, Raleigh, USA, ${ }^{2} \mathrm{CNR}$ Institute for Coastal Marine Environment, Naples, Italy, ${ }^{3}$ University of Brest, Brest, France,

${ }^{4}$ Stockholm University, ${ }^{5}$ Plymouth Marine Station, ${ }^{6}$ Danish Technical University, Copenhagen, Denmark
} 
Fig. 1. The 18 study-site locations of the testing and development of the SAF (from SPICOSA 2007). The geographic names are on the left and the corresponding two primary policy issues on the right. $\mathrm{N}=$ nitrogen.

\section{SPICOSA STUDY SITE LOCATIONS}

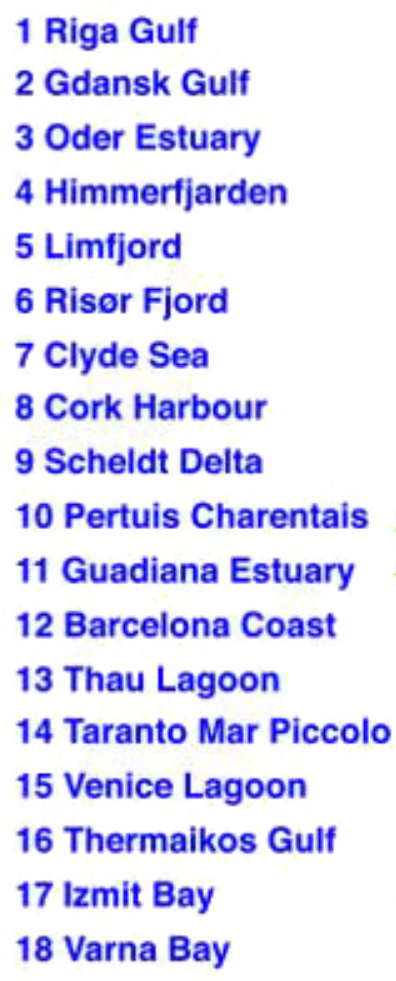

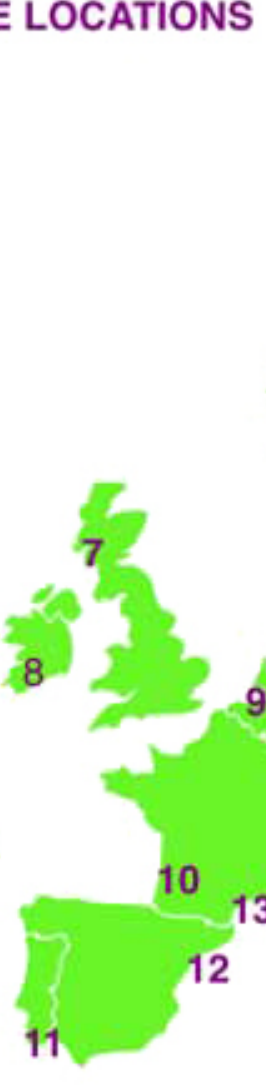

\author{
$\sqrt{2}$
}
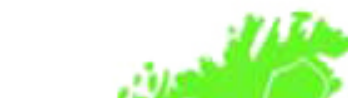

\section{PRIMARY POLICY ISSUES}

\author{
1 Pikeperch \& Fishing
}

2 Water Quality \& Tourism

3 Aquaculture \& $\mathrm{N}$-loading

4 Water Quality \& Sewerage

5 Mussels \& $\mathrm{N}$-loading

6 Cod \& Recreation fishing

7 Aquaculture \& Marinas

8 Marinas \& $\mathrm{N}$-loading

\section{Agriculture \& $\mathrm{N}$-loading}

10 Freshwater \& Agriculture

11 E-coli \& Bathing

12 Discharges \& Beach Quality

13 Seafood \& Pathogens

14 Mussels \& Waste Discharge

15 Clams \& Fishery

16 Mussels \& Fishery

17 Water Quality \& Real Estate

18 Water Quality \& Tourism goals and the information and actions needed to implement or modify them. A re-scaling of its application may alter the composition of the suite of interconnected problems, but not the underlying approach to addressing them. We tested the SAF on coastal-zone systems; however, its application to other complex systems would alter the composition of the suite of interconnected problems, but not the underlying approach to addressing them.

The SAF uses simulation analysis to investigate how coastal systems function and respond to external inputs. It uses a collaborative approach among the researchers, policy makers, and stakeholders. By treating a coastal zone as a microcosm, it offers a cost-effective mechanism for investigating a specific policy question relative to the entire system and for evaluating the potential consequences of different policy options. In this sense, the SAF has great practical value, i.e., by providing an objective, inexpensive instrument for testing policy options. It also has value in facilitating collaboration on decision making as well as in generating new knowledge about the simulated system. Simulation of "what if" questions in a complex system requires sophisticated transdisciplinary assessments of the interactions among the ecological, social, and economic dimensions and of the participatory links between them.

The research areas requiring the most learning and ultimately revealing the most research value were those associated with designing the virtual system to be simulated, formulating the key interactions, and generating a participatory environment among the stakeholders. The breadth of expertise needed was greater than most of the partners could offer and required a significant learning experience for both the individual and institutional participants. Hopkins and Bailly (2012) argue that these skills and assessment capacities are part of the emerging field of sustainability science. In brief, the SAF methodology requires three skills:

1. Using systems thinking to set up and interpret a simulation analysis, 
Table 1. Categories of values demonstrated by study-site applications (first column) and for each value a descriptor of knowledge gained (second column).

\begin{tabular}{|c|c|}
\hline Value & Knowledge gained \\
\hline GOVERNANCE & - including legal, social, and economic aspects. \\
\hline Policy effectiveness & Improved understanding of policy effectiveness or of the potential value of policy options. \\
\hline Issue conflicts & $\begin{array}{l}\text { Clearer definition of conflicts and information helpful for their resolution; evaluation of risks and costs } \\
\text { generated by human activities responsible for resource exhaustion and degradation. }\end{array}$ \\
\hline Sustainable development & Action or information that could advance the sustainability of a system, subsystem, or policy action. \\
\hline SUSTAINABILITY SCIENCE & - Contributing to transdisciplinary research in support of sustainable development. \\
\hline Systems thinking & $\begin{array}{l}\text { Perspectives gained by maintaining an holistic view of the coastal zone system while investigating the } \\
\text { function of subcomponents. }\end{array}$ \\
\hline Simulation analysis & $\begin{array}{l}\text { Quantification and understanding of the system's function, pattern of organization, and structure of } \\
\text { components. }\end{array}$ \\
\hline Science-policy interface & $\begin{array}{l}\text { Realization of actual or potential collaboration for sustainable solutions and achievement of knowledge } \\
\text { transfer to policy, stakeholders, and the public. }\end{array}$ \\
\hline SIMULATION ANALYSIS TOOLS & $\begin{array}{l}\text { - Regarding simulation models and resulting analyses as a mechanism for enriching research and } \\
\text { promoting collaborative dialog. }\end{array}$ \\
\hline Ecological component & $\begin{array}{l}\text { Combining methods and knowledge to represent and quantify the function of a natural system, its } \\
\text { cause-and-effect chains, internal interactions, and its external links. }\end{array}$ \\
\hline Economic component & $\begin{array}{l}\text { Valuation methodology appropriate for market and non-market activities, links between ecological and } \\
\text { social systems, and improved strategies for self-regulation of economic activities. }\end{array}$ \\
\hline Social component & $\begin{array}{l}\text { Understanding the social milieu and its dynamic role in determining public preferences; using a } \\
\text { collaborative approach for policy effectiveness; facilitating the acceptance of science for guiding } \\
\text { sustainable development. }\end{array}$ \\
\hline
\end{tabular}

2. Conducting transdisciplinary assessments of the interactions between the ecological, social, and economic dimensions, and

3. Engaging participation of stakeholders, ensuring their collaboration with researchers, and communicating the $\mathrm{SAF}$ results to a broader public.

\section{KNOWLEDGE GAINED}

\section{Systems Approach Framework Value Categories}

The SAF aimed to improve the science-policy interface by invigorating multidisciplinary research for the assessment of complex systems. To summarize the achievements of the study sites, we categorized the values demonstrated into three main groups: governance, sustainability science, and simulation analysis tools (Table 1). Examples of study-site results for each category are given in the following subsections, each identified by its geographic name (Fig. 1) and a reference.

\section{Governance}

The SAF experiments uncovered obstacles to policy effectiveness through conflicts among human activities, public resistance, and the lack of a planned approach to policy. Three themes important to effective policies concern: (1) appreciating the degree of connectivity between multiple coastal-zone issues, (2) understanding the system dependence of these issues, and (3) a balanced consideration of public needs. These themes overlap because, even if seemingly similar issues arise in different coastal zones, they cannot always be resolved in a similar manner due to differences among coastal zones in composition, pattern, and function.

\section{Policy Effectiveness}

Poor effectiveness in the handling of an issue may be caused by the absence or lack of a clear policy, by an inappropriate policy, or by weak enforcement and ineffective governance mechanisms.

Oder Lagoon. Recent research questions whether existing measures for reducing nitrogen loading in the Oder watershed could solve eutrophication problems and reduce nitrogen export to the Baltic Sea. The study-site team showed that, whereas harvesting nutrients by intensive mussel aquaculture in the Lagoon could be a helpful supportive measure, solving the problem would require greater coordination of policies in the full river-estuary system (Schernewski et al. 2012).

Gdansk Gulf. The transboundary Vistula River watershed creates a "dirty" plume along tourist beaches of the Gulf. This impacts local tourism and its derived income. However, local policies cannot solve the problem because the policy makers in the catchment area producing the wastes come under different jurisdictions (Hania Ladkowska, personal communication).

Varna Bay. When tourism increased enormously in the postSoviet period, no measures were taken to protect the water quality of the bathing beaches. The deterioration of bathing beaches eventually hampered the continued development of tourism. By contrasting the expense of additional combined 
sewer installations with the potential loss of tourist income, the study-site team was able to activate stakeholders and city officials to seek a solution (Moncheva et al. 2012).

Mar Piccolo. The city of Taranto had approved an expansion of mussel farms and relocated half of the existing sewage outfalls outside of the lagoon. The SAF analysis demonstrated how these policies acted synergistically to reduce the quality and profit of the mussel farming and demonstrated public support for more sustainable options (Caroppo et al. 2012).

\section{Issue conflicts}

When two harvesting human activities compete for a resource, the risk of over-extraction increases and conflict resolution through policy becomes difficult. Human activities involved in substance dumping or habitat destruction contribute indirectly to conflicts with other human activities and require a more difficult policy intervention.

Venice Lagoon. Open-access growth of the Venetian clam fishery created social (profit uncertainty, illegal fishing) and ecological (benthic damage, exposure to toxins) problems. Local institutions responded by promoting a planned aquaculture alternative that became very controversial. The SAF analysis demonstrated that a sustainable aquaculture could both satisfy the social and ecological concerns and provide acceptable incomes for the fishermen (Melaku Canu et al. 2011).

Limfjord. A three-way conflict existed between the traditional mussel fishers, faced with reduced mussel biomass due to decreases in nitrogen loading, expanding mussel aquaculture, and disputes with nature conservationists. The SAF analysis defused the conflict by presenting a clearer description of the dynamics through its scenario simulation results (Dinesen et al. 2011).

Guadiana Estuary. Policy differences between Portugal and Spain complicate the development of an integrated, transboundary plan for the Guadiana River and Estuary. The study-site team demonstrated that cooperation among Portuguese stakeholders, planners, and scientists provided a common understanding of how to improve water quality in the Guadiana through waste-water treatment, creating a better basis for future agreement with Spain (Guimarães et al. 2012).

Barcelona Coast. Social and natural systems conflict in artificial beaches where aesthetic and recreational appeal is favored over historical ecosystem services, such as fisheries and their nursery habitats. The long-term resilience of such a regime is questionable given the substantial resources (energy, biomass, money) needed to maintain it (Tomlinson et al. 2011).

\section{Sustainable development}

In the absence of a policy plan, single-issue or unbalanced policies can create or exacerbate ancillary problems with costly consequences. Progress is often blocked by the difficulty of assessing management options of common-pool resources.

Scheldt Delta. The relationship between nitrogen loading and eutrophication in the estuary is well studied, but the mixing of nitrogen from different sources in the river makes it difficult to quantify them individually and hence to formulate fair and efficient policies. The SAF application quantified the nonpoint and point sources of nitrogen in sufficient detail to resolve its apportionment and indicates that successful load reduction would require also reducing domestic urban sources (Vermaat et al. 2012).

Pertuis Charentais. The provision of an analytical framework for complex common-pool resources, which made explicit the objectives, rules, and operational agreements of the local water policy, was a major contribution to understanding user conflicts over freshwater distribution in the area (Mongruel et al. 2011).

Risr Fjord. The simulation analysis of the trade-offs between the development of tourist fishing for income and the conservation of the local cod population changed the dialog and opened up further options for developing a naturalresource-based tourism (Moksness et al. 2011).

Cork Harbor. The wide variety of human activities along the shoreline of Cork Harbor creates complex ecological, economic, and social pressures on the coastal resources that make sustainable development difficult to implement. The study-site team generated local interest in its approach and showed how the SAF might be used to construct a sustainable management plan for Cork Harbor that would incorporate the additional marina facilities desired by stakeholders. (Jeremy Gault, personal communication).

\section{Sustainability Science}

\section{System thinking}

The ability to view a system as a network of relationships that can have emergent properties of either added or decreased value helps in selecting policy options that will be effective in a complex system and in gaining the consent of stakeholders representing varied local interests. The absence of systems thinking makes policy vulnerable to being ineffective and inefficient.

Izmit bay. By assessing waterfront property differentials to demonstrate strong public appreciation of water quality, the study-site team alerted the municipal authorities to a potential a tax-revenue source for covering the cost of upgrading wastewater treatment (Tolun et al. 2012).

Oder estuary. Asking whether nitrogen removal by recycling nutrients from aquaculture (zebra mussel) to agriculture (as fertilizer) would be cost effective and more sustainable than by subsidizing nitrogen removal in the watershed revealed an 
incoherency in the regional governance concerning eutrophication in the estuary (Schernewski et al. 2012).

Loch Fyne. By recognizing the need to understand the subtle conflicts among the mixed authorities governing the area, the study-site team greatly improved its effectiveness in communicating and fostering collaboration with the stakeholders (Tett et al. 2012).

Thau lagoon. Combining macro-economic and dynamicpollution models of the lagoon at the local level provided an effective, integrated assessment of the risk of microbiological contamination and facilitated the evaluation of scenarios with different local development patterns and management strategies (Mongruel et al. 2012).

\section{Simulation analysis}

The ability to describe and quantify the dynamics of policy options through simulation analysis increased the credibility of the stakeholders and their willingness to collaborate. That the SAF can be easily modified for further applications reassured managers and stakeholders that the researchers were creating a potential for continued science-based decision making.

Thermaikos Gulf. By analyzing the problems of the Chalastra mussel farmers with declining harvests, illegality, and environmental limitations, the study-site team helped them understand their situation and provided them with a tool to explore sustainable options for improving mussel production (Konstantinou et al. 2012).

Limfjord. The potential to optimize the competing harvests of wild and farmed mussels and to better adapt to decreasing nitrogen loading brought clarity, reduced conflicts, and demonstrated the value of objective quantification for furthering cooperation (Dinesen et al. 2011).

Pertuis Charentais. The simulation of soft institutional change in governing the freshwater resources demonstrated that innovative collective arrangements involving farmers is an alternative to conventional, restrictive top-down measures for allocating water-use rights. It also showed how improved user practices within a multi-user community could help mitigate broader user conflicts in the coastal zone (Mongruel et al. 2011).

Thau Lagoon. The governance component of the dynamic contamination model for the lagoon was sufficiently flexible to simulate changes in its monitoring system and in the protocols that lead to administrative decisions. This allowed the pollution impact assessment to distinguish clearly between real contamination, observed contamination, and risk management (Mongruel et al. 2012).
Science-policy interface

The study sites differed markedly in their level of interaction between stakeholders and researchers. Despite this, all the study sites showed a clear trend of increasing enthusiasm and acceptance of the importance of stakeholder participation and the value of scientific guidance for decision making.

Loch Fyne. The study-site team successfully used a "communication space" (Habermas 1981) for promoting the understanding and deliberation of the policy issue and its scenario solutions. This opened up the discussion by reducing the protective attitudes that result from the institutional interests of stakeholders and disciplinary interests of the researchers (Tett et al. 2012).

Thermaikos Gulf. The study-site team found a lack of communication among authorities and between authorities and stakeholders. The model simulations brought managers, scientists, and mussel farmers together for the first time to discuss model scenario results that quantified aspects of the mussel farming. The SAF thus provided a sound basis for dialog and evaluation of the consequences of different management options (Konstantinou et al. 2012).

Himmerfjärden. The active participation of stakeholders from the start of the eutrophication modeling led to greater acceptance of its results, better agreement in the description of the problem, and clarity on the policies likely to be successful in its mitigation. It also paved the way for a continued, more formalized stakeholder participation in the management of the area through the establishment of a water council (Franzén et al. 2011).

\section{Simulation Analysis Tools}

\section{Ecological}

A principal goal of the SAF was to develop assessment tools organized around an impact in an ecological system. The benefits derived stemmed from a better understanding of the functional relationship between the impact and its cause. This provided the quantitative basis for the necessary links to the economic and social responses to the impact required for simulating policy options.

Scheldt Delta. By coupling the computer softwares ExtendSim and PCRaster, the research team greatly improved the capacity of the SAF to evaluate spatially explicit problems, such as where different policy measures would be most efficiently and cost-effectively implemented and how diverse farm practices affect non-point nitrogen discharges in a complex agricultural-urban watershed (Vermaat et al. 2012).

Mar Piccolo. A deterministic formulation of the estuarine circulation allowed researchers to simulate its conservative properties (salinity, circulation, diffusion) as functions of their input forcings. This physical certainty greatly assisted in the 
simulation of non-conservative properties subject to chemical-biological processes (e.g., nutrients), as well as phytoplankton and mussel production (Caroppo et al. 2012).

Venice Lagoon. The coupled models for a space-time distribution of biogeochemical properties, which included a bio-energetic model for clam growth, a dynamic population model for clam density, and a bioaccumulation model for toxins in clams, provided a defendable quantification as a basis for economic and social analyses in support of sustainable management of the clam fishery (Melaku-Canu et al. 2011).

Risr fjord. Stochastic methods and a historic database were used to simulate cod recruitment in the fjord. This was then used to portray the sensitivity of the cod population to environmental factors relative to controls on fishing pressure (Moksness et al. 2011).

Limfjorden. Time-series data of nutrient loadings and phytoplankton biomass (spring and autumn) were used to construct an annual empirical model to link primary production to growth of the wild-benthic and suspendedfarmed mussel populations and relate this to policy scenarios for nutrient regulation and fishing practices (Dinesen et al. 2011).

\section{Economic}

The goal of both the economic and social analyses was to demonstrate assessment methodologies and provide an indication of the value gained by linking them within the SAF application. The methods and their results served more as social-value indicators, rather than exact monetary values.

Izmit Bay. The study-site team combined a contingent valuation to reveal the willingness to pay for better quality of coastal waters with a hedonic pricing of real estate to demonstrate the value of proximity to the sea and of water clarity. This survey revealed a significant public willingness to pay (taxes) for improved water quality and a potential mechanism for obtaining public funding for improved wastewater treatment (Tolun et al. 2012).

Gdansk Gulf. The prices for rooms in hotels along the eastern beaches were compared with the water quality at increasing distances from the Vistula River plume in the Gulf. The gradient of these prices and the public perception of beach quality as a driver for tourist visits provided an estimate of the benefit lost by water pollution. As a major Gdansk sewage outfall discharges underneath the plume, the study-site team could demonstrate an income offset for relocating the outfall (Hania Ladkowska, personal communication).

Guadiana estuary. The application of an economic model demonstrated the value of the SAF to stakeholders and decision makers of the estuary through the quantification of the chain reaction among improved water quality, investment in eco-labels, impacts on the local economy, employment indicators, and changes in resident and tourist populations (Guimarães et al. 2012).

Limfjorden. An economic study of changes in the mussel fishery, due to nutrient reduction and introduction of linemussel culture, showed an increase in total harvestable mussel biomass and higher profit due to the higher value of mussels from line-cultures (Dinesen et al. 2011), even though economics of scale were restricted by the size of the plots in the licensing system (Ahsan and Roth 2010).

Barcelona coast. The assessed impact of deteriorated water quality on revenues and employment in the local businesses of the beaches was lower than the cost of feasible mitigation methods (e.g., underground storm-water collectors). However, non-market valuation techniques (travel cost method) clearly revealed a higher "economic" cost of poor water quality (Tomlinson et al. 2011).

Social

The social analyses focused on public perception and stakeholder participation and how these influenced decisionmaking. These methods are less well developed at present, but their value was clearly demonstrated.

Himmerfjärden. Establishing a participation function for estimating the willingness of farmers to create wetland buffers in the fjord catchment at different levels of economic support, gave results that could be used for policy design and provide opportunities for farmers to contribute to policy-making (Franzén et al. 2011).

Mar Piccolo. Through the use of Facebook, the study-site team impressed the Taranto city authorities by gaining public recognition of the study and increasing public awareness of the need for better resource management. In addition, it demonstrated an alternative mechanism to quantify public perception and potential participation in efforts for sustainable development (Caroppo et al. 2012).

Barcelona coast. Maintaining the artificial beaches while using them as sites for combined sewerage outfalls weakens the costbenefit feedback loop in which the attraction of the beach brings more clients to the local establishments and encourages the city to improve the beach water quality. A survey found this feedback loop to be weak because the use of the beaches and their commercial establishments are not a strong function of the water quality (Tomlinson et al. 2011).

\section{Effect on European Union Research}

We conducted an informal survey of the primary authors of the study-site publications cited above to determine whether the SAF exercise has made EU research more multidisciplinary and useful to society. The results in Table 2 indicate a consensus that the use of the SAF process has led to an improvement in the science-policy interface, use of the systems approach, stakeholder engagement, and support for 
Table 2. Results of a questionnaire distributed to the authors participating in the study sites $(n=29)$ on how the experience of the SAF applications influenced their research.

\begin{tabular}{lc}
\hline \hline Helpful qualities from your SAF research experience & Percentage \\
\hline Are you convinced that science should reach out to better inform policy and the public? & 95 \\
Did the SAF broaden your research experience? & 92 \\
Would you like to join a SAF users group and/or attend SAF workshops? & 85 \\
Was the stakeholder participation a positive aspect to pursue in future SAF applications? & 85 \\
Did your institute favor the multidisciplinary aspect of the SAF, i.e., integrating ecological, social, and economic research? & 84 \\
Did constructing the simulation models increase your understanding of your coastal zone? & 82 \\
Were you able to use the SAF experience to promote future research opportunities? & 78 \\
Do you now have a different opinion on the type of data that should be acquired to analyze the function of your coastal zone? & 77 \\
Have you used your SAF experience for advisory work? & 54 \\
Have you used your SAF knowledge for teaching or training purposes? & 53 \\
\hline
\end{tabular}

continued SAF applications contingent on funding support for research and training. The SAF was clearly a learning experience for the participating researchers, albeit not always fully appreciated until its completion.

\section{WIDER PERSPECTIVES}

Several aspects of sustainable development were enriched and clarified by the SAF experiments. Although not new, we feel that they need further definition and discussion among those interested in resource management, governance, and sustainable development.

\section{Governance Characteristics}

The SAF uses a broad definition of governance (cf. Bell 2002) that encompasses those controlling mechanisms that exert authority over social behavior, namely: legal rules (regulation/ enforcement), social norms, cultural paradigms (social milieu), and economic pressures (market/income). The effectiveness of governance is directly addressed in SAF applications by taking these mechanisms into account and by exploring the strategies that policy might use to promote sustainable development. The design phase addresses stakeholder interests, while the appraisal phase considers public perception, market pressures, and non-market values to ascertain their influence on the valuation of policy scenarios.

\section{Policy effectiveness}

Policy effectiveness varies among coastal zones, due to local differences in how the controlling governance mechanisms are manifested, e.g., non-statutory organizations, market influences, or cultural practices. The response to each of these mechanisms also varies in scale (from local to regional to international). The lack of coherency between policy directives at different scales was often cited as a problem in the study-site results. Thus, policy applied at one scale may fail to bring about change in cases where opposing governance mechanisms operate at another scale. This helps explain why policy effectiveness depends on the local system, why broad stakeholder collaboration is essential to policy effectiveness, and why policy enforcement is resisted when stakeholders are sidelined in the policy-making process.
A SAF application requires an initial understanding of the function of governance in a coastal system in order to analyze and simulate policy effectiveness. Toward this end, the SAF involves information of several types:

- It evaluates the effectiveness of existing legal aspects by exploring them in the context of the local governance, determining their causal links to environmental impacts, and their associated social-economic responses.

- It uses simulation analysis of policy scenarios in order to evaluate which policy options are effective for addressing a policy issue.

- As a precautionary tool, it can both assess how the existing policy interacts within the system and evaluate the risks and costs to the system relative to a stated objective.

- It includes public perception surveys to uncover how and why the public supports or resists a policy option.

This information and the stakeholder participation process provide a basis for constructing a systematic resource plan for a coastal system.

\section{Policy Issues}

\section{Distribution}

Through its initial mapping of the governance, the SAF identifies those human activities that cause the impact involved in the studied policy issue, as well as the responses to this impact (cf. Hopkins et al. 2011). This exercise inevitably discloses a complex set of interacting human activities that cannot be ignored even if only a single policy issue is examined. Hopkins and Bailly (2012) categorized the causal human activities identified for each study-site policy issue into four areas of human influence according to how they interact with the coastal zone system (Table 3). They found that eight were related to wasting (substance dumping), six to harvesting (substance removal), four to modifying (habitat destruction), and none to conservation (protecting system function). No two study sites with the same environmental issue had the same 
Table 3. Policy issues addressed by the 18 study sites (cf. Fig. 1), listed in the vertical panels according to the areas of human influence: wasting, harvesting, modifying, and conservation (see text). Each study site had at least three issues pertaining to the ecological component and two issues pertaining to each of the economic and social components (from Hopkins and Bailly 2012). None of the SSAs chose a primary policy issue related to conservation, although some had it as a secondary issue. WWT = Waste-Water Treatment, $\mathrm{N}=$ nitrogen

\begin{tabular}{|c|c|c|c|c|c|}
\hline \multicolumn{6}{|c|}{ Distribution of policy issues for each area of human influence and for each ecological, social and economic dimension } \\
\hline \multicolumn{6}{|c|}{ WASTING } \\
\hline ECOLOGICAL & 24 & ECONOMIC & 16 & SOCIAL & 16 \\
\hline Pollution & 6 & Public Costs of WWT & 6 & Trans-Boundary Conflicts & 3 \\
\hline Nitrogen Loading & 5 & Tourist Income & 4 & Ecosystem Health & 2 \\
\hline Aquaculture & 3 & Costs of N-loading & 2 & Public Costs of WWT & 2 \\
\hline Eutrophication & 3 & Employment Potential & 2 & Recreational Benefits & 2 \\
\hline Transparency & 3 & Fishery Income & 1 & Seafood Contamination & 2 \\
\hline Urban/Storm Runoff & 3 & Habitat Conservation & 1 & Tourist Employment & 2 \\
\hline \multirow[t]{4}{*}{ Harmful Algae } & 1 & & & Directives & 1 \\
\hline & & & & Public Costs of N-loading & 1 \\
\hline & & & & User Conflicts & 1 \\
\hline & \multicolumn{3}{|c|}{ HARVESTING } & & \\
\hline ECOLOGICAL & 18 & ECONOMIC & 12 & SOCIAL & 12 \\
\hline Fish Population & 4 & Fishery Income & 5 & Ecosystem Health & 3 \\
\hline Aquaculture Shellfish & 3 & Habitat Conservation & 2 & Habitat Conservation & 2 \\
\hline Fishing Practices & 3 & Public Costs of WWT & 2 & Public Costs of N-loading & 2 \\
\hline Benthic Habitat & 2 & Costs of N-loading & 1 & Public Costs of WWT & 2 \\
\hline Nutrient Loading & 2 & Public Costs of WWT & 1 & Shore Property Values & 1 \\
\hline Harmful Algae & 1 & Tourist Income & 1 & User Conflicts & 1 \\
\hline Pollution & 1 & & & Seafood Contamination & 1 \\
\hline Transparency & 1 & & & & \\
\hline Storm Runoff & 1 & & & & \\
\hline \multicolumn{6}{|c|}{ MODIFYING } \\
\hline ECOLOGICAL & 12 & ECONOMIC & 8 & SOCIAL & 8 \\
\hline Ecosystem Health & 3 & Agricultural Income & 2 & Recreational Benefits & 3 \\
\hline Employment & 2 & Costs of N-loading & 2 & User Conflicts & 3 \\
\hline User Conflicts & 1 & Employment Potential & 2 & Directives & 1 \\
\hline Habitat Conservation & 1 & Freshwater Scarcity & 1 & Trans-boundary Conflicts & 1 \\
\hline Seafood Contamination & 1 & Costs of WWT & 1 & & \\
\hline Cultural Values & 1 & & & & \\
\hline Property Values & 1 & & & & \\
\hline Recreation Potential & 1 & & & & \\
\hline
\end{tabular}

ancilliary issues and none had conservation as a primary issue, although some considered this as a secondary issue.

\section{Human activities}

Understanding how human activities interact with an ecosystem helps explain the complexity facing the resource manager who attempts to solve environmental problems. Each causal category of human activity generates a different type of interaction with other components of the system, such that if the primary issue were treated independently, the result could negatively influence attempts to implement sustainable solutions. Thus, the multi-issue complexity reduces the effectiveness of single policy directives and even of efforts to enforce the same policy over a set of coastal systems. Hopkins and Bailly (2012) point out that the human activities that cause a disturbance are not always those experiencing the response, eliminating direct feedback loops that could connect the two or more human activities involved. Importantly, when more than one human activity is involved, the lack of constructive connections between them creates conflicts. Furthermore, multi-issue assessments of long-term benefits and losses are made even more difficult when multiple interactions are involved. Some examples from the study sites follow:

Wasting. Activities that discharge substances into a river (for example, agriculture) may have no direct connection with activities harvesting biological production in the estuary. An activity discharging toxins will not voluntarily regulate the discharge or publicize the potential threats to the system, a task left to researchers, policy makers, or members of the public. When media exposure forces policy makers to officially recognize a pollution problem, delaying actions often follow, due to high costs for cleanup, uncertainty of proof of source, or of risk to humans and their activities.

Harvesting. Activities that harvest an estuary (e.g., fishing) may ignore the risk of exceeding sustainable yield, because the socioeconomic system temporarily buffers or absorbs the loss of a specific fishery. Industrial fisheries can adapt to such 
losses by increasing effort, through switching to alternative fisheries, and using technical improvements or subsidies (htt p://www.fishsubsidy.org/), all of which promote further overfishing (Pauly 2006).

Modifying. Activities that change the shoreline (e.g., marina construction) may have strong short-term economic incentives, but may pollute the habitat or weaken fish recruitment, by affecting nursery habitats. Conventional environmental impact studies often ignore important nonmarket consequences of such trade-offs by omitting the costs of long-term loss of habitat (e.g., resilience, biodiversity) and by considering only short-term benefits (e.g., increased economic activity).

\section{Managing recovery}

The continued provision of environmental goods and services is of primary interest to society. To secure this, research must understand the internal feedback loops that sustain the system's structure and productivity and the biodiversity that makes it resilient to external and internal perturbations. For example, Jackson (2001) has described how many marine systems have declined through a sequence of metastable states (loss of large pelagic animals, loss of benthic habitat structures, and emerging predominance of microbial regimes). Some of these phase shifts were understood and even anticipated. However, the concomitant loss in productivity useful to humans was mostly understood only in hindsight.

Managing a recovery requires good knowledge of the causality of the phase-shift, which inevitably involves more than one causal event or preconditioning trend, as with Atlantic cod (Choi et al. 2004). The desired recovery will be uncertain because the necessary conditions cannot be exactly known. The causal information on these phase shifts includes the inherent non-linearities in the systems' dynamics (e.g., feedback loops, tolerances, biodiversity changes) that are an essential component of resilience and crucial for understanding the ecological thresholds that precipitate phase shifts and result in degraded states and loss of value to humans (Groffman et al. 2006, Lyytimäki and Hildén 2007). When major disturbances occur, the current state and resilience of the system determine the degree to which it can return to its previous state or adapt to a new equilibrium state (Gunderson and Holling 2002). In coastal-zone systems, a phase shift in the ecosystem can cause changes in dependent social and economic components that further complicate adaptation (e. g., Hildén, 2006).

\section{Self-regulating human activities?}

The variables causing disturbances by humans often coincide with natural variables, making it difficult for management to sort out which human activity is responsible for which environmental impact. Identifying risks and determining causes are both objectives of a SAF simulation analysis. However, identification of sources of disturbances is not sufficient, nor is simple regulation of these sources, because to be sustainable these human activities must have in place stabilizing feedback loops to control excessive disturbances, without which the ecosystem will continue to degrade.

Thus, a policy that focuses only on the environmental component and ignores all the human activities that create strong disturbances cannot achieve environmental homeostasis. Often a significant proportion of these activities lies outside the purview of local authority and are unwilling or not inclined to voluntarily self-regulate the disturbances they create (Fig. 2). This occurs most commonly when activities are subject to external governance mechanisms, thereby creating an obstacle to local policy planning. Resolution is possible through establishing statutory links with larger-scale governance and/ or collaborative links with the economic influences involved.

Fig. 2. Human activities in most coastal zone systems lack functional feedback loops with the environment that they are impacting. This requires that either policy regulate these activities, or that the activities themselves become sustainably self-regulating, i.e., with regard to their impacts on natural and social subsystems of a coastal system. The black arrows designate the human activities that use the environmental system. The solid orange lines indicate the indirect feedback loops that policy might establish for the three categories of destabilizing human activities, and the orange dotted line is an additional potential direct feedback for Harvesting. The dark purple arrows indicate market influences on the human activities. The dark green arrows are the potential information feedback loop of the SAF.

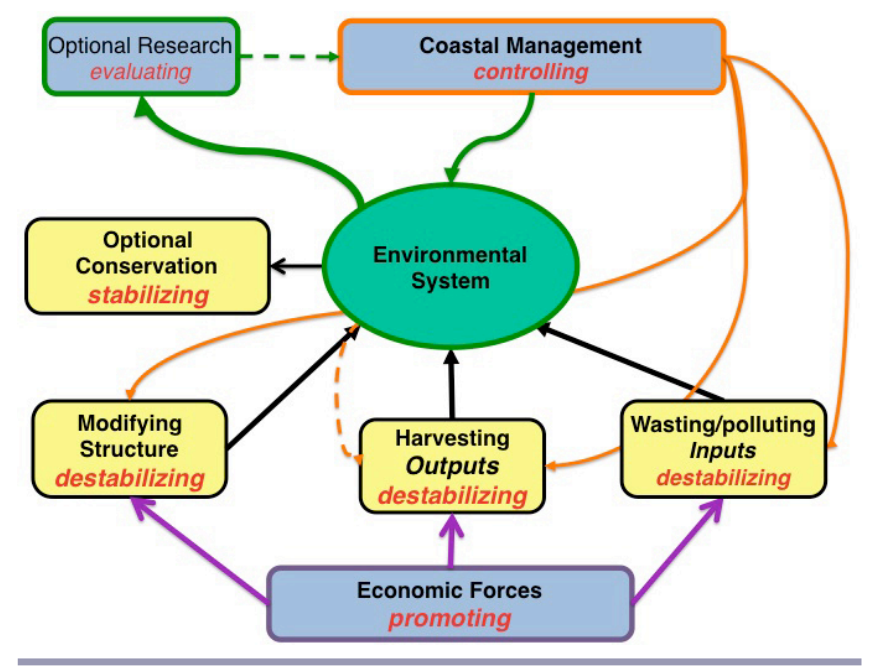

A management strategy intending to improve an ecosystem's resilience should consider those policy options that would strengthen the negative feedback loops controlling the harmful human activities, that increase the ecosystem's resilience to anthropogenic disturbances, and that lower the waste 
throughputs. Strict regulations or pollution trade credits are often used to force a human activity to reduce its damaging influences. These lack sophistication, are often seen as punitive, and cause conflicts with policy makers. A SAF application can test cooperative strategies and technical options in the context of sustainable development where incentives for the transformation of human activities are based on assessments that include the short-term costs for alleviating disturbances and on the long-term benefits of preserving the ecosystem function.

\section{Sustainable Development}

\section{Public perception}

There is an important difference between sustainability and sustainable development. The former conveys a vague goal, perhaps suggestive of great sacrifice for an impractical, utopian end that directly conflicts with the natural striving of humans to improve their social and material status. In contrast, sustainable development implies a dynamic process of improvement in the relationship between humans and nature by conserving natural capital and by promoting goals that favor social over economic capital. Sustainable development conveys a practical shared process based on common good, in line with the altruistic side of human nature. Both researchers and the public are better equipped to assess progress with sustainable development than with realization of sustainability itself, because sustainability is inherently more subjective, as in the difference between the questions: "Are you getting richer?" or "Are you rich?"

Society's valuation of a scientific product often depends on how the public accepts it (subjectively) and not necessarily on how the scientific community views it (factually). For example, the value of more equitable societies can seem obvious, without resorting to facts, solely based on beliefs of what is right for human society. In considering an unfamiliar problem, like arresting climate change, which cannot be easily understood, the facts tend to be ignored and judgments rest on subjective evaluations of the information source. In a democratic decision process when the facts are unfamiliar, a judgment on their verity will often reflect subjective arguments more than factual. Recognizing this, the SAF places great emphasis on providing relevant information in an accessible form to the public. The practical logic and urgency for the transition to sustainable development require an extensive cognitive process, where facts, empirical knowledge, beliefs, and peer consensus must all enter in a nonconflicting way. In the critical area of public acceptance, success stories become strong agents for change. For the many that advocate sustainable development, gaining and supporting acceptance is seen as the most immediate global challenge (Ehrlich 2010).

\section{Need and urgency}

Public acceptance of a problem also depends strongly on the perceived need, urgency, and feasibility of its solution. The issue of sustainability becomes crucial when a society approaches its limits for social or resource reasons (Diamond 2005). Finding a solution to an unfamiliar problem may be impossible without sufficient warning, cooperation, and a transition plan. The global need and urgency for greater sustainability derives from unsustainable trends (overconsumption and overpopulation) that will inevitably force a societal phase shift from a demand-based to a resource-based system. We currently have an institutional and ideological mix of these two strategies that seem to be directed toward two organizational end options: a plutocracy based on competition and resource hoarding, or a sustainable society based on cooperation and resource sharing. The former better represents the current global society, but the latter choice is better supported on moral grounds, and can also be supported on scientific grounds, with cooperation and competition working together at different levels: system and component, respectively (cf. Odum 1995). Globally, we are tracking progress (e.g., Ewing et al. 2010, United Nations 2011) but still lack sufficient awareness, willingness to cooperate, and a plan for global reorganization.

\section{Vulnerability}

Complex systems are vulnerable to sequences of large disturbances particularly when one occurs before the full recovery from a previous one-causing an accumulative erosion of the resilience of the entire system. Within the last 10 years, a sequence of global disturbances has occurred: e. g., the 2001 9/11 attack, the 2003 "Iraq oil war," the 2008 credit collapse, and currently, the "Arab spring," the foodprice spike, and the "oil peak." Knowing this, it behooves us to try to better understand the complexity of our global system and estimate the risks of its collapse (Levin 1999).

Murray and King (2012) studied the behavior of crude-oil production relative to its price over the last 12 years. In a scatter plot (Fig. 3a), they show a portentous phase shift in the petroleum economy. Before 2005, rather steady increases in demand were matched by similar increases in production and price. However, for the next 6 years, the production has remained around 74 million barrels/day even though the price varied up to threefold higher. They interpret this loss of correlation between production and price as indicating a crude oil production ceiling, where production can no longer meet demand. Although it is arguable whether these indicators really herald an imminent "oil peak" or just reflect speculation and political tensions, the economic and human risk of ignoring this warning is potentially huge compared with the cost of conducting better simulations and of initiating sustainable solutions. This is an example of disconnect between objective assessments by science and subjective interpretations by special interests. It also indicates a lack of 
Fig. 3. (a) A scatter plot showing a distinct change in the relationship between oil production and oil prices over the last 12 years, from Murray and King (2012). This is interpreted as an indicator that, after 2005, production was no longer able to match rising demand, which is reflected by higher and more variable prices. (b) A 20-yr time series of the annual oil production, purple line - right axis, from (http://www.indexmundi.com). The rest of the plots are commodity indexes for food (yellow-green), fuel (red), composite commodities (blue), http://www.indexmundi.com/commodities/.

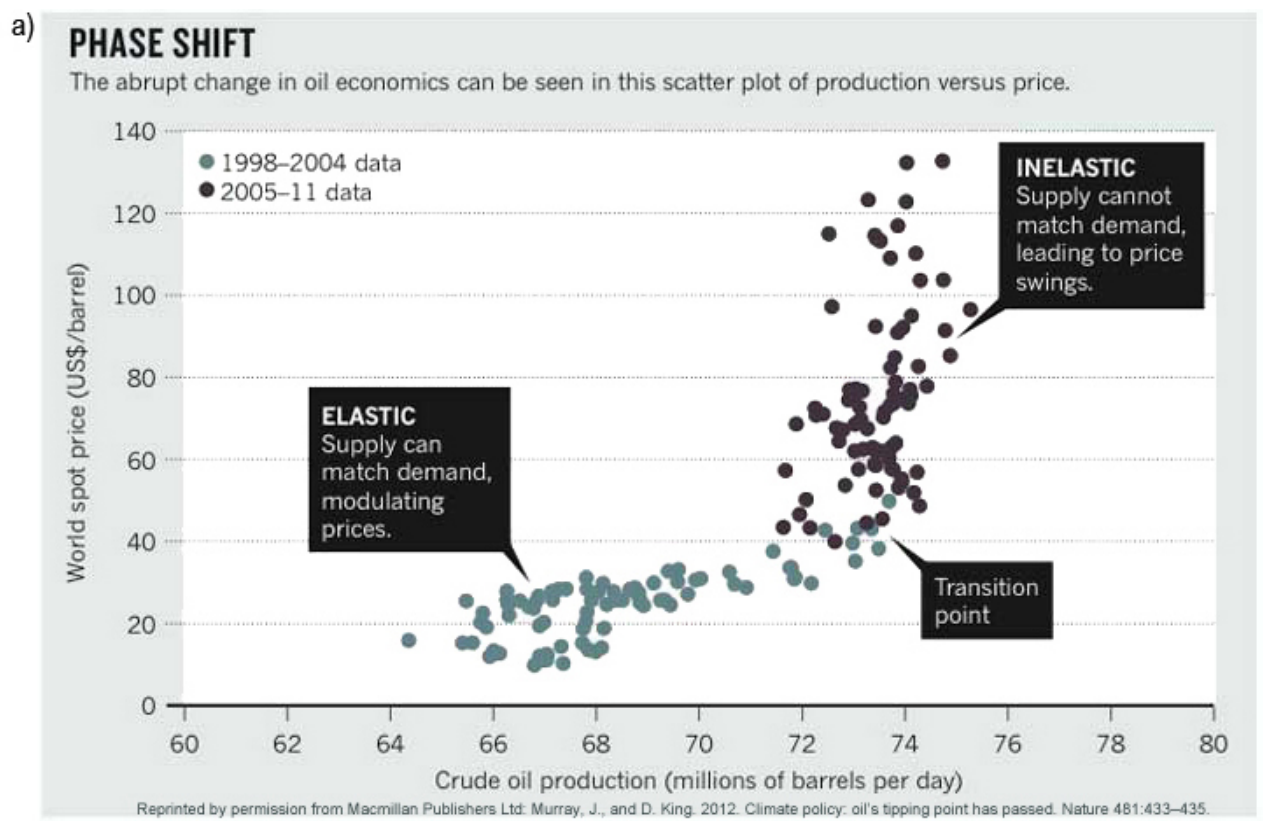

b)

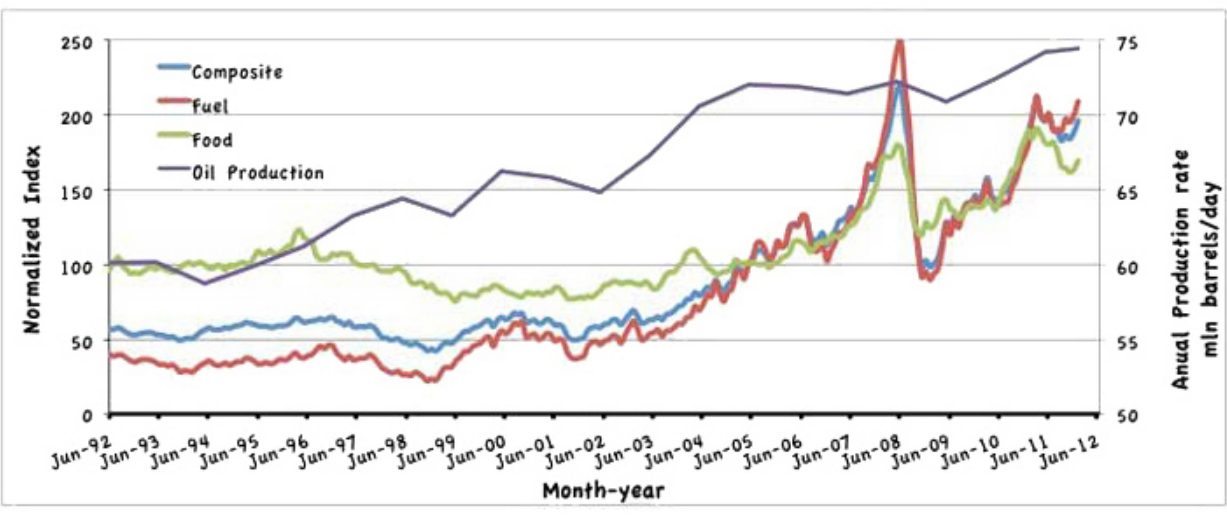

political will to intervene and a lack of governance structure at the scale required for resolution. Greater attention focused on this situation should catalyze concern for surpassing resource limits and for a global strategy of sustainable development.

Over the last 20 years, global prices of food and other commodities have correlated closely with oil prices and increased with the price of oil (Fig. 3b). The implication is that the threshold cost for human subsistence will increase with oil prices. In 2005, three billion persons lived on less than U.S. \$2.5 per day (http://www.globalissues.org/). A doubling of the cost of living could increase that number to five billion and seriously undermine recent improvements in food, education, and health in the developing world. The critical instability of the global condition is also made clear by the unsustainable trends in arable land, water availability, climate change, population increase, wealth disparity, ecosystem degradation and by continued nuclear proliferation, wars, and health-care deprivation. This situation of multiple interacting stressors urgently demands a better assessment of the risk of a cascading collapse of the resource systems that support our global society (cf. http://www.stwr.org/; Homer-Dixon 2006).

\section{Coastal Zone Systems}

\section{Linking scales}

The global need for sustainability underlines the scientific responsibility to better understand the complexity of our planetary system. It is strategically essential to make 
sustainability experiments on smaller-scaled systems to guide those on larger scales because the global transition must initiate at all scales, in anticipation that a self-organizing process will emerge at all scales.

Considering the extensive conflicts among components of coastal systems and the associated disconnects between human activities, the role of policy for sustainable development appears intractable. This is in part because we assume that it is the responsibility of policy to take the lead, and we are cynical about its ability to do it. In reality, this is a misconception. Top-down regulation may be temporarily essential but it should be balanced and provide an incentive to self-regulate through bottom-up collaboration. At the beginning and end of the process, the responsibility for sustainable development must be shared by all interacting components of society and be in resonance with natural systems to achieve optimal sustainable conditions.

\section{Sustainable networks}

From a sustainability point of view, each coastal zone system could constitute a hub of smaller-scaled open systems and each hub would represent an even smaller-scaled network of components (Fig. 4). By virtue of its external connections, a coastal hub would be itself embedded in an even larger scalefree network (Butts 2009). The goal of each hub would be to improve internal efficiency, minimize throughput waste, minimize social and economic friction, and maximize both social and natural capital. Such an objective would need to be simulated, with the appropriate data, to assist management decisions and the self-organizational processes. An important advantage of using the SAF for this goal is that the spatial boundaries of integration can be independent of those defined geographically, economically, and politically. Ostrom (2009) described the variables that facilitate self-organization of moderately scaled social-economic resource systems. These variables are largely confirmed in our findings and can be incorporated in a SAF application, i.e., a system's size, its productivity value, knowledge of its dynamics, cooperative interest and number of users, the amenability of its governance and economic drivers, and a provision for collective-choice management.

\section{CONCLUDING REMARKS}

The SAF experiments discussed here have emphasized insights on what is needed to promote sustainable management of coastal zones. Many of the results repeat and reinforce conclusions from the literature on the transition to sustainable development. Here, we summarize the SAF experimental results in the form of salient, perceived concerns and the contributions of the SAF toward resolving these concerns.
Fig. 4. Schematic of a coastal zone sustainability hub in a scale-free network. The sustainability objective is to internally minimize the combined throughput (waste) of its internal, open-system components and to connect to other external hubs such that the integrated throughput of the connected ensemble minimizes its combined throughput. Similarly, it connects with other hubs to minimize economic and social disparity.

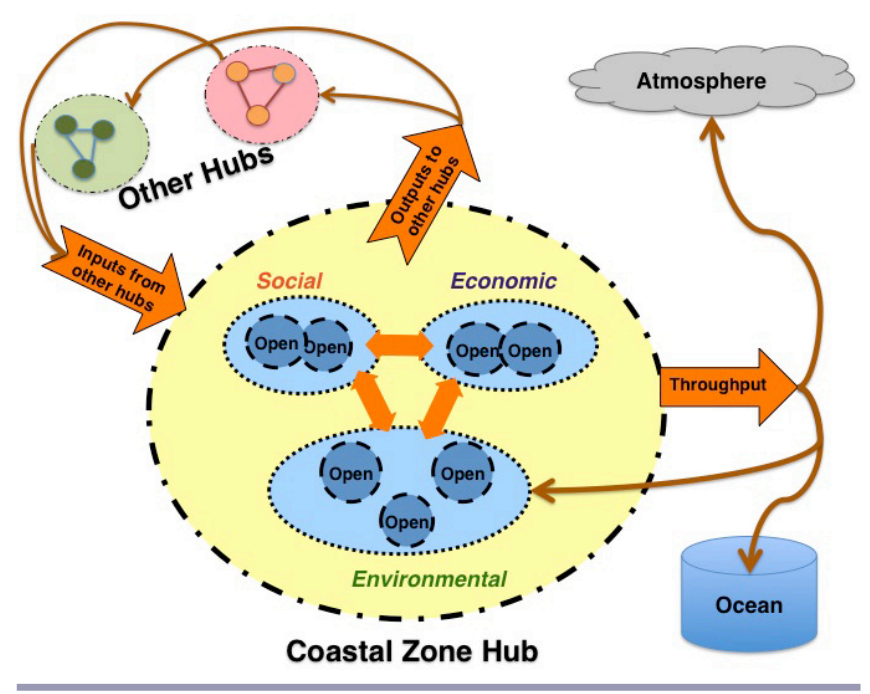

\section{Policy Effectiveness}

\section{Concerns}

Although policy is a direct instrument of governance, it is not always effective in promoting change. We found that policy effectiveness varied due to different institutional infrastructures and cultural differences regarding compliance and enforcement. Stakeholders often related that they had never had an open dialog with policy makers or researchers. The hierarchical scale of policy often creates confusion and conflicts or fails to properly address problems. We found that policy decision making on coastal issues is often not based on sound science, that sustainable development in many cases requires an ICZM plan, and that the difficulty of implementing such plans is a frequent source of frustration and alienation.

\section{Contribution}

By starting with a mapping of resources, uses, and governance, the SAF generates a holistic understanding of the connections and interactions of governance within a coastal zone system. This information integrates the interests of the stakeholders and facilitates consideration of governance issues when formulating the simulation analysis of a policy issue. The mapping methodology, which orders data to enable the simulation of a policy issue, is a contribution that merits further improvement. The SAF negotiates a policy issue with 
stakeholders, based on mutual interest and resource limits, and forms a relationship that then continues through the SAF application. The value of this procedure was increasingly appreciated during the applications at the different study sites. The partnership was a mutual learning experience for researchers and stakeholders. Most environmental managers, policy makers, and stakeholders directly involved had not previously experienced the type and quality of information that can be generated through simulation analyses. Their appreciation for this information was confirmed by their interest in continued use of the SAF, either in house or through institutional collaboration.

\section{Systems Approach}

\section{Concerns}

Although greatly improved computer capabilities are driving a resurgent use of the systems approach for complex systems in other fields, its application to human-environmental systems lags. This can be ascribed to the over-specialization of disciplinary research, lack of transdisciplinary career and publication opportunities, and differences in terminology and methods between social and natural sciences. Initially, we had difficulty assembling multidisciplinary study-site teams and met some hesitancy in support by research institutes, as well as reluctance among researchers to broaden their disciplinary expertise. There was limited expertise in the systems approach among the researchers available for the SAF experiments. We anticipate that the learning curve will shorten with further SAF applications and reports on their results.

\section{Contribution}

The value of the systems approach is the capacity to answer functional questions about complex systems. However, its application cannot be converted to a cookbook procedure. This is because every system has a different architecture (composition and function) making the end product different. It takes "systems thinking" skill to make the derived information relevant to the information goal. To facilitate this learning process, we provided a preliminary "best-guess" procedure for the study sites to guide their applications. This procedure was then refined through feedback reports from the researchers. The results are presented in this volume and in the online SPICOSA handbook (http://www.coastal-saf.eu/). We have developed academic courses and generated curricula in sustainability science to introduce potential users to this learning experience. We also found it important to explain the process to the participating stakeholders and, for this reason, we have provided training modules in SAF use for practitioners at all levels of participation (http://www.spicosa. eu/setnet/index.htm). The SAF contribution is an evolving methodology dedicated to understanding and diagnosing complex social-ecological systems. It is not a modeling effort to provide end-users with "panacea models" for solving sustainability problems (cf. Ostrom et al. 2007). The difference is important, in that the SAF simulation analysis is system and user specific and that the end-user is a partner in the process.

The specific research contributions from the SAF experiments mostly relate to the methods and information needed to improve the simulation analysis and its user partnership. We allude to these briefly in the following.

Simulation. A question frequently asked of a system concerns its response to a change in present conditions (inputs, policy, and use). The answer is an educated approximation, one that can be refined through better data or methods. When applied to a policy issue of a static system, the question can be answered by its past behavior; however, this "business-asusual" case is mainly useful as a comparative reference. For a dynamic system, the changes occurring within the system must be simulated well enough such that the difference in response to a policy option will be discernible from that of the reference condition. Asking the right question, correctly formulating the system, and interpreting the results require systems-thinking skills. What one learns from simulating a scenario will generally be useful, even when it does not exactly address the initial question: e.g., by revealing other questions and options.

Data Input. The SAF applications used only data already collected for other purposes. These were often inadequate, requiring researchers to simplify simulations by intelligent approximations, a process that underlined the need for data specifically designed for systems modeling. Many ecosystem analyses lacked land-runoff flows and their substance concentrations at daily-seasonal time scales and/or adequate data on biological production and internal biogeochemical processes. Most economic analyses lacked time-series data and information on how their activities (through harvesting, wasting, or modifying) impact the coastal zone system. Nearly all the social analyses lacked adequate dynamic surveys of public perception and behavior for establishing social links to economic and ecosystem changes, attitudes toward governance, wellbeing, etc. We agree with Ostrom (2009) that system-specific monitoring and compatible, multidisciplinary databases are essential and need improvement to increase our capacity to analyze complex social-ecological systems.

Non-linearities. Most of the simulations included some type of non-linear interaction, but often encountered difficulty in representing them for lack of good supporting time-series data to validate processes involving, e.g., tolerances, thresholds, predator-prey relationships, disturbances, illegality, public acceptance, etc.

Links among ecological, social, and economic components. Establishing and quantifying the links between these components was new research territory for all. The conceptual diagrams were successful in depicting the social-economic responses to the simulated ecosystem impact. Quantifying this required specifying the transformation variables that link 
components, which was accomplished well enough to illustrate the value of doing so. That is, we were able to render these links comprehensible to the stakeholders, e.g., between tourism and water quality, fish harvest and growth, public perception and ecosystem value.

Social-economic valuation. The methods for non-market valuations were also fairly new to policy makers and stakeholders. They were important in the communication process by disclosing some of the reasons for the negative public reaction to seeking short-term benefits or stopgap solutions, such as over-development without planning, and by providing arguments for improved community cooperation.

Cooperative partnership. Testing ideas for improving the science-policy interface was a major objective of the SAF development. A key factor was the initial establishment of a working collaboration with managers and stakeholders around the shared goal that formed a truly transdisciplinary research team. The benefits were, e.g., increased familiarity, improved exchange of information, and an erosion of the perceived aloofness of science. Repeated discussions with the stakeholders helped the researchers tune their presentations toward a more balanced sharing of information in a commonspace dialog (cf. Mette 2011)

\section{Sustainable Development}

\section{Concerns}

Most of our findings on the public perception of policy and the possibility that science could assist in sustainable development were positive, with a cynical touch, e.g., "sounds great, but it will never happen here." This illustrates a lack of faith that authorities will strive for public long-term interests and perhaps that science is likely to have a voice. Similarly, there exists a malaise about the stability of global or national situations and a cynical outlook for their political or economic resolution. However, a strong public interest persists for generating sustainable solutions, particularly at local levels.

\section{Contribution}

A functioning science-policy interface is critical to managing a rapidly changing planet. Our results provide evidence that a combination of systems thinking, simulation analyses, and stakeholder participation is feasible and can be effective in promoting sustainable solutions. The fact that large-scale scientific warnings, in the form of trends (in biodiversity, coral reefs, etc.) and simulations (of climate, resources, populations, etc.) have failed to stimulate policy into taking preventative action emphasizes our failure as a society to incorporate objective science into management and as researchers to provide convincing simulations of policy options based on comprehensive monitoring of the interactions between societal and ecological systems.

We set out to develop a common, low-cost methodology for planning and evaluating options for sustainable development in coastal zone systems. Even with a game plan, this was difficult due to the complexity of interactions between human activities and the resource system that supports them. As in chess, one needs to plan far beyond the next move. Understanding how a system reacts, therefore, becomes a valuable asset to instituting change. Sustainable development can start with any system, and can make a contribution at any level, but it is always limited by the interactions with externalized components. Use of the SAF provided a comprehensive set of coastal planning experiences, which we anticipate will serve as useful examples for the furtherance of coastal sustainable development and ICZM globally. At a broader scale, we hope that adaptations of the SAF will serve as a transdisciplinary research tool for understanding complex systems, a vehicle for testing management options, and an avenue for partnering the general public for sustainable societies.

Responses to this article can be read online at: http://www.ecologyandsociety.org/voll7/iss3/art39/ responses/

\section{Acknowledgments:}

The authors wish to acknowledge the 6th FP of the European Commission (RTD Climate change and Ecosystems call) for its foresight and funding in the form of farsighted objectives to stimulate research toward the needs of the evolving EU community. We are especially grateful for the support of the three coordinating Institutes IFREMER, France, IAMC, Italy, and UBO, France, and the 51 other partner institutes and organizations from 22 countries in the SPICOSA Consortium. Most of all, we thank the several hundred researchers and the excellent Node and Work Task leaders who have contributed, persevered, and brought an optimistic enthusiasm to the completion of the Integrated Project SPICOSA. In addition, we would like to acknowledge our separate institutions for their real and implicit support for the editorial efforts spent on this volume, as follows in order of authorship: Department of Marine, Earth, and Atmospheric Sciences, NCSU, USA and Institute for Marine Coastal Environment, IAMC/CNR, IT; European Institute for Marine Studies, UMR-AMURE, UBO, FR; Department of Systems Ecology, Stockholm University (Baltic Ecosystem Adaptive Management program), SE; School of Marine Science and Engineering, PU, UK; Faculty of Social Science, BU, NO; and Section for Coastal Ecology, $D T U, D K$.

\section{LITERATURE CITED}

Ahsan, D. A., and E. Roth. 2010. Farmer's perceived risks and risk management strategies in an emerging mussel aquaculture industry in Denmark. Marine Resource Economics 25(3):309- 
323. http://dx.doi.org/10.5950/0738-1360-25.3.309 http://dx. doi.org/10.5950/0738-1360-25.3.309

Bell, S. 2002. Economic governance and institutional dynamics. Oxford University Press, Melbourne, Australia.

Butts, C. T. 2009. Revisiting the foundations of network analysis. Science 325:414-416. http://dx.doi.org/10.1126/scie nce. 1171022

Caroppo, C., L. Giordano, N. Palmieri, G. Bellio, A. Paride Bisci, G. Portacci, P. Sclafani, and T. Sawyer Hopkins. 2012. Progress towards sustainable mussel aquaculture in Mar Piccolo, Italy. Ecology and Society 17(3):10. http://dx.doi.or g/10.5751/ES-04950-170310

Choi, J. S., K. T. Frank, W. C. Leggett, and K. Drinkwater. 2004. Transition to an alternate state in a continental shelf ecosystem. Canadian Journal of Fisheries and Aquatic Science 61:505-510. http://dx.doi.org/10.1139/f04-079

Diamond, J. 2005. Collapse. Viking Books, New York, New York, USA.

Dinesen G. E., K. Timmermann, E. Roth, S. Markager, L. Ravn-Jonsen, M. Hjorth, M. Holmer, and J. G. Støttrup. 2011. Mussel production and water framework directive targets in the Limfjord, Denmark: an integrated assessment for use in system-based management. Ecology and Society 16(4):26. http://dx.doi.org/10.5751/ES-04259-160426

Ehrlich, P. R. 2010. The MAHB, the culture gap, and some really inconvenient truths. PLoS Biology 8(4): e1000330. http://dx.doi.org/10.1371/journal.pbio.1000330

Ewing, B., A. Reed, A. Galli, J. Kitzes, and M. Wackernagel. 2008. A calculation methodology for the national footprint accounts. Global Footprint Network, Oakland, California. [online] URL: http://www.footprintnetwork.org/

Fiksel, J. 2006. Sustainability and resilience: toward a systems approach. Sustainability: Science, Practice, and Policy 15 (2):15-21. http://dx.doi.org/10.1109/EMR.2007.4296420

Franzén, F., G. Kinell, J. Walve, R. Elmgren, and T. Söderqvist. 2011. Participatory social-ecological modeling in eutrophication management: the case of Himmerfjärden, Sweden. Ecology and Society 16(4): 27. http://dx.doi.org/10. 5751/ES-04394-160427

Gallopin, G. 2003. A systems approach to sustainability and sustainable development. United Nations Publication, LC/L 1864-P, United Nations, New York, New York, USA.

Groffman, P., J. S. Baron, T. Blett, A. J. Gold, I. Goodman, L. H. Gunderson, B. M. Levinson, M. A. Palmer, H. W. Paerl, G. D. Peterson, N. L. Poff, D. W. Rejeski, J. F. Reynolds, M. G. Turner, K. C. Weathers, and J. Wiens. 2006. Ecological thresholds: the key to successful environmental management or an important concept with no practical application? Ecosystems 9:1-13. http://dx.doi.org/10.1007/s10021-003-0142$\mathrm{z}$ http://dx.doi.org/10.1007/s10021-003-0142-z

Guimarães, M. E., A. Mascarenhas, C. Sousa, T. Boski, and T. Ponce Dentinho. 2012. The impact of water quality changes on the socio-economic system of the Guadiana Estuary: an assessment of management options. Ecology and Society 17 (3):38. http://dx.doi.org/10.5751/ES-05318-170338

Gunderson, L., and C. Holling, editors. 2002. Panarchy: understanding transformations in human and natural systems. Island Press, Washington, D.C., USA.

Habermas, J. 1981. Theorie des kommunikativen Handelns. Suhrkamp, Frankfurt am Main, Germany. Translated by T. McCarthy as: The theory of communicative action. Volume 1 (1984): Reason and the rationalization of society. Volume 2 (1987): Lifeworld and system: a critique of fundamentalist reason. Beacon Press, Boston, Massachusetts, USA.

Hildén, M. 2006. Thresholds and risks-tensions between policies and biological effects. Pages 109-113 in A. Pistocchi, editor. Ecological and human health risk assessment: focusing on complex chemical risk assessment and identification of highest risk conditions. Institute for Environment and Sustainability, Ispra, Italy. [online] URL: http://nomiracle.jrc. it/

Homer-Dixon, T. 2006. The upside of down. Island Press, Washington, D.C., USA.

Hopkins, T. S., and D. Bailly. 2012. The role of science in the transition to sustainability: the systems approach framework for integrated coastal zone management. in E. Moksness, E. Dahl, and J. Stttrup, editors. Integrated coastal zone management. Second edition. Wiley-Blackwell Ltd., in press.

Hopkins, T. S., D. Bailly, and J. G. Stttrup. 2011. A systems approach framework for coastal zones. Ecology and Society 16(4):25 http://dx.doi.org/10.5751/ES-04553-160425

Jackson, J. B. 2001. What was natural in the coastal oceans? Proceedings of the National Academy of Science 98:S23-S32. http://dx.doi.org/10.1073/pnas.091092898 http://dx.doi.org/1 $\underline{0.1073 / \text { pnas.091092898 }}$

Konstantinou, Z. I., Y. N. Krestenitis, D. Latinopoulos, K. Pagou, S., Galinou-Mitsoudi, and Y. Savvidis. 2012. Aspects of mussel-farming activity in Chalastra, Thermaikos Gulf, Greece: an effort to untie a management gordian knot. Ecology and Society 17(1):1. http://dx.doi.org/10.5751/ES-04455-170101

Levin, S. 1999. Fragile dominion: complexity and the commons. Perseus Books, New York, New York, USA.

Lyytimäki, J., and M. Hildén. 2007. Thresholds of sustainability: policy challenges of regime shifts in coastal 
areas. Sustainability: Science, Practice, and Policy. 3(2):6168.

Melaku Canu, D., P. Campostrini, S. Dalla Riva, R. Pastres, L. Pizzo, L. Rossetto, and C. Solidoro. 2011. Addressing sustainability of clam farming in the Venice lagoon. Ecology and Society 16(3):26. http://dx.doi.org/10.5751/ES-04263-160326

Mette, A. 2011. Bridging the gap between science and society. Pages 103-135 in P. Tett, A. Sandberg, and A. Mette, editors. Sustaining coastal zone systems. Dunedin Academic Press, Edinburgh, UK.

Moksness, E., J. Gjøsæter, G. Lagaillarde, E. Mikkelsen, E. Moland Olsen, H. T. Sandersen, and J. Helge Vølstad. 2011. Effects of fishing tourism in a coastal municipality: a case study from Risør, Norway. Ecology and Society 16(3):11. http://dx.doi.org/10.5751/ES-04290-160311

Moncheva, S., E. Racheva, L. Kamburska, and J. D'Hernoncourt. 2012. Environmental and management constraints on tourism in Varna Bay, Bulgarian Black Sea coast. Ecology and Society 17(3):35. http://dx.doi.org/10.5751/ ES-05107-170335

Mongruel R., J. Prou, J. Ballé-Béganton, M. Lample, A. Vanhoutte-Brunier, H. Réthoret, J. A. Pérez Agúndez, F. Vernier, P. Bordenave, and C. Bacher. 2011. Modeling soft institutional change and the improvement of freshwater governance in the coastal zone. Ecology and Society 16(4):15. http://dx.doi.org/10.5751/ES-04294-160415

Mongruel, R., A. Vanhoutte-Brunier, A. Fiandrino, F. Valette, J. Ballé-Béganton, J.A. Pérez Agúndez, N. Gallai, V. Derolez, S. Roussel, M. Lample, and T. Laugier. 2012. Why, how, and how far should microbiological contamination in a coastal zone be mitigated? An application of the systems approach to the Thau lagoon (France). Journal of Environmental Management, in press.

Murray, J., and D. King. 2012. Climate policy: oil's tipping point has passed. Nature 481:433-435. http://dx.doi. org/10.1038/481433a http://dx.doi.org/10.1038/481433a

Odum, H.T. 1995. Self-organization and maximum power. Chapter 28. Pages 311-364 in C. A. S. Hall, editor. Maximum power: the ideas and applications of H.T. Odum. Colorado University Press, Niwot, Colorado, USA.

Ostrom, E. 2009. A general framework for analyzing sustainability of social-ecological systems. Science 325:419422. http://dx.doi.org/10.1126/science.1172133

Ostrom, E., M. A. Janssen, and J. M. Anderies, 2007. Going beyond panaceas. Proceedings of the National Academy of Science 104(39):15176-15178. http://dx.doi.org/10.1073/ pnas.0701886104 http://dx.doi.org/10.1073/pnas.0701886104
Pauly, D. 2006. Major trends in small-scale marine fisheries, with emphasis on developing, and some implications for the social sciences. Maritime Studies (MAST) 4(2):7-22.

Schernewski, G., N. Stybel, and T. Neumann. 2012. Zebra mussel farming in the Szczecin (Oder) Lagoon: water-quality objectives and cost-effectiveness. Ecology and Society 17 (2):4. http://dx.doi.org/10.5751/ES-04644-170204

Tett, P., Sandberg, A., and A. Mette. 2011. Sustaining coastal zone systems. Edinburgh, Dunedin Academic Press.

Tett, P., B. Valcic, T. Potts, C. Whyte, F. Culhane and T. Fernandes. 2012. Mussels and yachts in Loch Fyne, Scotland: a case study of the science-policy interface. Ecology and Society 17(3):16. http://dx.doi.org/10.5751/ES-04995-170316

Tolun, L. G., S. Gamze, S. Ergenekon, A. Murat Hocaoglu, A. S. Donertas, T. Cokacar, S. Husrevoglu, C. Polat Beken, and A. Baban. 2012. Socioeconomic response to water quality: a first experience in science and policy integration for the Izmit Bay coastal system. Ecology and Society 17(3):40. http://dx.d oi.org/10.5751/ES-04984-170340

Tomlinson, B., S. Sastre, D. Blasco, and J. Guillén. 2011. The systems approach framework as a complementary methodology of adaptive management: a case study in the urban beaches of Barcelona. Ecology and Society 16(4):28. http://dx.doi.org/10.5751/ES-04484-160428

United Nations. 2011. The millennium development goals report. United Nations, New York, New York, USA.

Vermaat, J. E., S. Broekx, B. Van Eck, G. Engelen, F. Hellmann, J. De Kok, H. Van der Kwast, J. Maes, W. Salomons, and W. Van Deursen. 2012. Nitrogen source apportionment for the catchment, estuary, and adjacent coastal waters of the River Scheldt. Ecology and Society 17(2):30. http://dx.doi.org/10.5751/ES-04889-170230 